\title{
Specialist training: national coherence and consistency
}

Specialist training is a challenging, complex process. Individuals who embark on specialist training make an enormous commitment and rightly expect the support, guidance and encouragement necessary to successfully complete the process. In addition the public need specialists who are trained to consistent high standards.

To meet the expectations of specialist trainees, beyond local trainee/trainer arrangements and relationships, the stakeholders of specialist training in dentistry must be coherent and consistent in fulfilling their respective roles and responsibilities. In the UK, the Joint Committee for Specialist Training in Dentistry (JCSTD) exists, first and foremost, to facilitate nation-wide coherence and consistency in the provision of high quality training in the thirteen specialties recognised by the General Dental Council (GDC). The work of the JCSTD has been underpinned since 1996 by a document widely referred to as the Accord.

\section{UPDATED ACCORD}

Over the last twelve to eighteen months the Accord has been updated to take account of the many, varied changes to, in particular, the roles and responsibilities of the stakeholders of specialist training. The updated document (available on the GDC website - www.gdc-uk.org), is cast in the form of a Memorandum of Understanding (MOU) and viewed as an interim, 'living' document to be continuously reviewed and updated to take account of evolving arrangements in specialist training, as well as the continuum of postgraduate dental education. The specialist training MOU documents the roles and responsibilities in specialist training of the GDC and its expert body on specialist training in dentistry - the Specialist Dental Education Board (SDEB), the Postgraduate Dental Deans and Directors (PDDDs), both individually and collectively through COPDEND - the Committee of Postgraduate Deans and Directors (UK), the Dental Faculties of the Royal Surgical Colleges and their Joint Meeting of Dental Faculties (JMDF), the universities represented on the JCSTD through the Dental Schools Council (DSC, formerly the Council of Heads and Deans of Dental Schools (CHDDS)), the Specialist Advisory Committees (SACs) of the JCSTD, relevant specialist societies and associations and, of course, the JCSTD itself.

\section{INFORMING WORKFORCE PLANNING}

By working in accordance with the arrangements and relationship set out in the specialist training MOU, stakeholder input to specialist training will be facilitated, enhanced and, most importantly, in the eyes of trainees be both transparent and joined-up. PDDDs will have responsibility for the quality management of programmes of specialist training, with the SACs of the JCSTD being advisory through, in all probability SAC panels comprising members familiar with SAC policies and thinking spread across the UK. Through close working between SACs and the lead PDDDs for the various dental specialties, national databases of trainees will be maintained. These databases will help inform future workforce planning.

Stemming from discussions to develop the specialist training MOU, stakeholders have gone on to flesh-out detailed arrangements, for example, to clarify revised arrangements to establish new programmes of training and, where appropriate, determine the length of training programmes for individuals with relevant prior learning and experience. This work is part of the ongoing evolution of specialist training across the UK.

With its nation-wide remit, the JCSTD is driven by the need for continuous improvement in the commonality, robustness and effectiveness in specialist training across the UK. To this end the specialist training MOU is fundamental to future success and as such, a critical document in securing the future sufficiency of specialist training and, in turn, the protection of the public requiring specialist care.

DOI: $10.1038 /$ sj.bdj.2008.876 